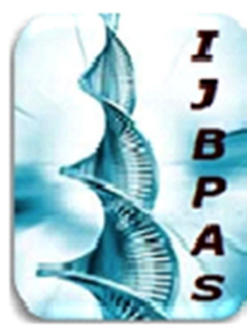

International Journal of Biology, Pharmacy and Allied Sciences (IJBPAS) 'A Bridge Betusen caboratorymd QReado'

Www.iibpas.com

\title{
IMPROVEMENT OF MENTAL HEALTH AND NUTRITIONAL STATUS IN COVID- 19 PATIENTS WITH NUTRIENTS AND HERBS - A REVIEW
}

*Corresponding Author: Dr. Luxita Sharma: E Mail: lshrama@ggn.amity.edu , lakshita1982@gmail.com Received $16^{\text {th }}$ June 2021; Revised $11^{\text {th }}$ July 2021; Accepted $25^{\text {th }}$ Aug. 2021; Available online $25^{\text {th }}$ Jan. $_{2022}$

https://doi.org/10.31032/ijbpas/2022/11.1.2043

\begin{abstract}
According to the World Health Organization, corona viruses have the ability of infecting not only mammals but can also affects birds. It is believed that the $2019-\mathrm{nCoV}$ is the third generation of the corona virus. Corona virus in humans can be differentiated based on their severity \& ability to spread. In case of pandemics, people might start practicing hypervigilance due to fear and anxiety of the disease, severity of which can even lead to posttraumatic stress disorder (PTSD) or even depression in worse conditions. Stressful situations and poor health behaviours which included- increased alcohol consumption, poor \& unhealthy intake of food, improper sleeping cycles, decreased physical activities, lead to distorted \& poor mental wellbeing. Increase in life stress always tends to affect the eating pattern of an individual leading to unhealthy eating, especially opting for foods which are high in fats and sugars.

The nutritional status of an individual helps in making the immune system strong enough to deal with illness during the COVID-19 pandemic. The effect of proper nutrition \& healthy nutrients intake on gene expression, cell activation, and signalling molecules modification leads to stronger immune system. The role of zinc, iron, and vitamins A, B 12, B6, C, and E in strengthening the immune system is much known. Including these nutrients properly in the daily diet is also one of the ways of handling the current situation. Mass lockdowns were witnessed during the pandemic which led to different impacts on health, many lifestyle changes were practised including changes in eating patterns, sleeping habits, and physical activity were done to deal with the situation.
\end{abstract}

Keywords: Food, Mental Health, COVID 19, Nutrition, Immune System, Nutritional Status 


\section{INTRODUCTION}

Towards the end of the year 2019, a novel and dangerous virus by the name of coronavirus surfaced China-Wuhan. The country of China was quick enough to inform the World Health Organization (WHO) about this outbreak and shared about the sequential information with the international community after discovering the causative agent. Last two decades saw the onset of severe acute respiratory syndrome coronavirus (SARSCoV) outbreak (2002) and the Middle East respiratory syndrome coronavirus (MERSCoV) outbreak (2012), which were the first two variants and had a very harmful effect on the human population earlier and acted as global threat (Syed, 2020).

Tyrell and Bynoe in 1966, were the first to describe the coronavirus as positive single strand RNA virus which was enveloped and had the power of infecting not only humans but also a large variety of animals. They produced the virus from the patients who were suffering from common cold. It was described. The name coronavirus comes from a Latin word "corona" meaning "crown", because the morphology of these virus resembles solar corona (spherical virions with a core shell and surface projections) (Tyrrell \& Bynoe, 1966).

This virus belongs to the family of Coronaviridae and sub family of
Coronavirinae. Till now the doctors have recognized around seven types of viruses that have the power to affect humans. The most common one being- 229E \& NL63 variants of alpha coronavirus and OC43 \& HKU1 variants of beta coronavirus. MERS$\mathrm{CoV} \& \mathrm{SARS}-\mathrm{CoV}$, strains of his virus are rare and are more damaging to human health. MERS-CoV strain causes Middle East respiratory syndrome (MERS), and SARS-CoV strain can cause severe acute respiratory syndrome (SARS). Another strain of SARS-CoV by the name of SARSCoV-2 started circulating in the year 2019, which became the cause of the COVID19 disease (Cui et al, 2019; Chan et al, 2020). There are four known existing subfamilies of the corona virus- alpha, beta, gamma, and delta. While mammals (especially bats) are considered as the main source of origin of the alpha and beta variant, gamma and delta viruses are said to be originated from birds \&pigs. Further if we discuss about the different subtypes of the corona viruses, it was found that the beta virus is the most dangerous out of all the seven subtypes that have the power to affect human health adversely \& is even fatal. While the alpha variant can only cause infections that can be either asymptomatic or will show mild symptoms only (Zhou et al, 2022). Despite belonging 
to the same beta virus subgroup, the genomic structures of the covid-19 and SARS-CoV viruses were only $70 \%$ similar with the novel group being genetically different from the virus SARSCoV. The covid-19 epidemic also had its outbreak during the China Spring Festival, same as that of the epidemic SARS. Since during this festival huge number of visitors travelled in and out of the country, it acted in favour of this highly contagious disease for the transmission of the disease worldwide (Shrikrushna et al., 2020 \& Sze et al, 2020).

In the third month (March) of the year 2020, covid-19 disease spread across all the countries, making people sick and causing massive deaths all around the globe. In order to tackle this alarming situation and slow down the mass spread of this disease, many countries chose to enforce restrictions on public life by practicing $\&$ adhering to social distancing norms.

\section{Transmission}

The most common mode of this virus transmission was found to be air. When an infected person sneezes or experiences coughing, the virus is transmitted to the other individual who is in close physical contact with the person. Any form of physical contact-handshakes, touching contaminated things or surface and then without washing hands, touching one's nose, eyes, or lips, can lead to the transmission of virus. Although, there are rare chances of contamination of the disease through faeces. The virus holds the ability to affect the individual throughout the year, but majority of increase in the infection rate was seen during the season of fall and winters as these climatic conditions were found to be more favourable for the transmission. Not only adults but children are also at risk of being infected by one or more subtypes of virus throughout their life (Rabi et al, 2020).

The Covid-19 disease should not be confused with an airborne infection, only the mode of transmission of the disease is contact with the respiratory droplets from the infected person. The size of the respiratory droplets is large and will only be able to affect the other individual if they encounter the droplet from within 2 metres of distance. Whereas, in the airborne infection, even small droplets can transmit the infection by floating through the air currents to long distances and can remain active for long duration under specific temperature and humid conditions. In case of corona virus, when the infected respiratory droplets falls on any surface, the possibility of transferring the infection from the surface to the individual is high as it can be easily transferred by touch. As per different studies, the chances of 
transmission of other beta-coronaviruses, such as those on SARS and MERS, from inanimate surfaces such as glass, metal, or plastic are high, and the virus can live on from 2 hours up to 9 days on the infected surface. Cold and dry environmental conditions have shown to increase the virality of these viruses (Van et al, 2014 \& Kampf et al, 2020).

\section{Classification of Covid-19}

The National Institutes of Health (NIH), classified the disease into five broad categories based their severity-

\section{Asymptomatic}

Infection:

Individuals with positive SARSCoV-2 positive individuals show no clinical symptoms.

2. Mild Illness: Individuals show symptoms of fever, headache, cough \& sore throat, malaise, muscular pain, nausea, vomiting, diarrhoea, insomnia etc. But no signs of shortness of breath \& abnormal chest imaging is seen in these cases.

3. Moderate Illness: Individuals who have their SpO2 levels lower than 94\% in normal room air and show signs of lower respiratory tract disease.

4. Severe Illness: Individuals with $\leq$ 94\% levels of $\mathrm{SpO} 2$ in room air; a ratio of partial pressure of arterial oxygen to fraction of inspired oxygen, $(\mathrm{PaO} 2 / \mathrm{FiO} 2)<300$ with marked tachypnea with respiratory frequency $>30$ breaths/min or lung infiltrates $>50 \%$.

5. Critical Illness: Individuals with acute respiratory failure, septic shock, or have multiple dysfunctional organs. Covid-19 patients can also become critically ill if they develop acute respiratory distress syndrome

(ARDS)

(Cascella et al, 2022).

\section{Effect of Virus}

\section{Pulmonary effects}

It was seen in most of the cases that the respiratory system was the most affected part of the patient infected by this virus. The most common cases were present with symptoms of upper respiratory tract infection (sore throat, cough, nasal congestion etc), pneumonia, severe pneumonia (with respiratory rate $>30$ breaths/min; severe respiratory distress or $\mathrm{SpO} 2 \leq 93 \%$ in room air) $\&$ in worse cases even ARDS (acute respiratory distress syndrome) was present (Chen \& Chen, 2020).

Management of respiratory insufficiency through different ways such as prone positioning to improve oxygen supply in normal cases \& providing oxygen via highflow nasal cannula, and non-invasive 
ventilation are among the most common therapies used to deal with the insufficiency (Sarma \& Calfee, 2020).

\section{Cardiac effects}

COVID-19 disease increases the chances of cardiac complications. These complications can occur even after the patient has overcome the corona infection and is under recovery. The chances of inflammation will be still high and can also evolve silently. Many survivors of the severe acute respiratory syndrome (SARS) disease were diagnosed with dyslipidemia, pulmonary fibrosis, and even avascular necrosis in the later stage of life. Patients with covid-19 were seen with signs of myocardial injuries, even myocardial ischemia/infarction (MI) and myocarditis. Other common cardiac manifestations included ACS, arrhythmias, cardiomyopathy, and cardiogenic shock (Zaim et al, 2020).

\section{Gastrointestinal effect}

Covid-19 disease even affects the Gastrointestinal (GI) tract of the individual. The most common discomfort experienced by the patients include appetite loss, nausea, vomiting, diarrhoea and abdominal pain or discomfort. These symptoms can be seen with or without the symptom of fever, myalgias, and cough (Han et al, 2020). Some patients also experience constipation as their stool tends to contain infectious virus intacted to it, making it difficult for the patient to pass the stool. Although the percentage of patients with these GI symptoms is very less, only up to one-half tends to shed the virus through stool. The levels of lactate dehydrogenase and other liver enzymes is seen to be increased in more than $1 / 2$ of the patients admitted with covid 19 infection, which also is an indicator of the liver or bile ducts injuries (Parasa et al, 2020).

\section{Effect on skin}

The disease of covid-19 also tends to cause skin manifestations (acne, eczema, psoriasis, and rosacea), like other viruses and chronic inflammatory diseases. The trunk was seen to be the most affected area of the patient with mild or no itching. Although no relation was found between the severity of disease and skin manifestations (Recalcati, 2020).

\section{Response of the Immune System}

The response of the immune system plays an important role in handling the susceptibility and severity of the covid-19 disease. Although weak immune system has been associated with increased chances of developing severe risk of covid-19, organ damage can be caused due to the hyperinflammatory response of the immune system to this infection. During the infection a rapid increase is seen in the inflammatory parameters - Interleukin-2, 
Interleukin-7, colony-stimulating factor 3, C-X-C motif chemokine ligand 10, MCP1, MIP-1 $\alpha /$ CCL3 and TNF alpha), due to imbalanced immune response which can further lead to cytokine storm or secondary hemophagocytic lymphohistiocytosis. Evidence also shows that hyperinflammatory response to the infection can also predict the morbidity and mortality in patients of the covid-19 disease (Mehta et al, 2020). It is necessary to screen the levels of ferritin, platelet count, ESR (erythrocyte sedimentation rate) and the H Score, for the patients suffering from the infection to screen them for hyperinflammation. If hyperinflammation is present, then it is advised to follow the therapeutic approach to lower down the immune activity. Still, it is a difficult to determine whether the treatment's antiinflammatory effect is outweighing the risk of impairing the immune system that is trying to fight the infection (Beeching et al, 2020).

\section{Effect of Covid 19 on Mental Health}

During the times of sudden outbreak of an unknown disease which is infectious, has unknown dangerous outcomes and with a lot of rumours going around it is obvious for the people to feel unsafe and worried at the same time (Ren et al. 2020). According to Cheng \& Cheung, 2005, during the outbreak of SARS, around $70 \%$ people in the city of Hong Kong, China had this anxious feeling of getting infected with SARS and felt that the chances of them getting infected was higher in comparison of catching just common cold infections (Cacioppo \& Hawkley, 2009; Chen \& Feeley, 2014)

This feeling of fear and anxiety in people due to any disease outbreak can lead to unfair or prejudicial treatment to a particular group of people or even country, as was seen in the case of Corona virus. Chinese people all around the world were blamed for the outbreak of the Covid-19 disease just because the outbreak started from the city of Wuhan, China. The media played an important role in creating this perception, the disease was many times addressed using the terms such as 'China virus', 'Wuhan virus' or the 'New Yellow Peril', knowingly or unknowingly creating a bubble in the mind of people and turning Chinese people as culprits for this situation (Ren et al. 2020).

Different people react to different situations in different ways. Fear is the most common way of responding to any kind of situation by common population

Also, during the Covid 19 disease a rise in the financial instabilities was experienced throughout the globe. Due to financial difficulties along with social isolation, rise in the cases of psychological problems 
became common. Increase in number of death cases due to substance abuse and suicide was seen. This risk was even bigger in numbers in patients who were already suffering from mental disorders such as dementia, mental illness, and autism. Anxiety, depression, and post-traumatic stress disorder (PTSD) were the most seen mental health problem symptoms in the patients recovered from the disease (Pfefferbaum \& North, 2020).

Feelings of despair, lost hopes, grief, pain of losing our loved ones to the disease, and loss of purpose was experienced by people all around the world because of pandemic. There was state of confusion mixed with lack of knowledge and fear due to mixed messaging from government or health officials (Han et al. 2018).

Effect of Covid 19 on Mental Health \& Food Intake

Most people throughout different countries tried to practice substantial lifestyle changes due to the stress and fear of getting infected by the virus and because of experienced bereavement.

Negative psychological feelings has been experienced by people practicing quarantine due to disease outbreaks earlier also. People experienced increased stress, anxiety, depression leading to poor psychological wellbeing and negative mental health during COVID-19 lockdown
(López-Bueno et al., 2020).Covid-19 lockdown also saw increase in number of children with poor diet intake \&deteriorating health (Pietrobelli et al., 2020).Due to the raised stress conditions during Covid-19 lockdown, increased practice of eating unhealthy food was experienced by people which in turn may have led to development of more negative mood over lockdown (Ball and Lee, 2000).

\section{Role of Healthy Nutritional Status}

Almost around 2,500 years ago, highlighting the value of healthy food intake, Hippocrates quoted- "Let food be thy medicine and medicine be thy food". The nutritional status of an individual can get easily affected by both of these factorsnutrient intake and disease incidences; thus, a healthy nutritional status is really important for maintaining a strong immune system. Improper intake or availability of food and presence of infections will lead to severe malnourishment making the body weak not only physically but mentally also (Bogoch et al., 2020).

This change also affected the mental as well as physical health and even somehow promoted sedentary lifestyle due to lesser physical activities and faulty eating habits. Fear and anxiety also played key roles in causing changes in dietary habits of people leading to unhealthy dietary intakes and 
decreased desires to consume food or even enjoy it (Aman \& Masood, 2020).

A balanced diet is very much important in every aspect of human health, even boosting the immune system to fight against the effect of deadly virus like corona. A proper dietary intake is necessary to make sure that the body is in the strongest possible state to battle the virus. A robust immune system can only be built if one practices proper and healthy diet, that is capable enough of fighting against any kind of virus. People who tend to consume well-balanced diets have better immune systems and are safe from infecting themselves from chronic diseases and infections (Sharma, 2020)

Apart from Vitamin C, till now there is no clinical proof that can support that fact that any other supplement can enhance the functioning of our immune system and help in the treatment and prevention of viral infections. Vitamin $\mathrm{C}$ is one of the major water-soluble vitamins and plays an important role on making the immune system strong. The RDA of Vitamin $\mathrm{C}$ is $90 \mathrm{mg}$ per day for men and $75 \mathrm{mg}$ per day for women ((Anton \& Miller, 2005).

The following guideline by Khayyatzadeh, 2020, can help in improving the immune system by boosting our immunity to fight through the Covid-19 situation:
- Daily consumption of fruits is necessary. One can choose from the list of guava, apple, strawberry, banana, cantaloupe melon, blackcurrant, pineapple, papaya, grapefruit, orange, longman fruit or pummelo. Try to include at least four servings of either fruits in your diet.

- Including fresh vegetables \& legumes, eg- green bell peppers, garlic, ginger, kale, lime, dried coriander, broccoli, green chili pepper, beans and lentils)- Up to 5 servings in a day.

- Eating whole grains and nuts, e.g.Grains- wheat, unprocessed maize, oats, millet, brown rice. Roots such as yam, potato, taro or cassava \& nuts like almonds, coconut, and pistachio.

- Consumption of Red meat can be restricted to one or two times and poultry twice or thrice per week. Food products made from animal sources e.g. fish, fish, eggs, and milk should be included in the diet.

- Foods high in fat, sugar or salt contents should be avoided. Irregular snacking should also be avoided.

- Overcooked vegetables tend to lose important nutrients such as vitamins 
and minerals Thus overcooking of veggies should be avoided.

- If choosing dried or canned fruits and vegetables, it is advised to go for thoses which have no added sugar or salt.

- Daily salt intake should not be more than 5 grams per day.

- Preference should be given to intake of unsaturated fats majorly found in avocado, fish, nuts, soy, olive oil, canola, corn oil, and sunflower, rather than saturated fats found in butter, fatty meat, coconut and palm oils, cheese, ghee, and cream.

- We should drink at least 8-10 glasses of water daily. Water not only helps in transportation of the nutrients in the blood, but also helps the body to get rid of waste and maintain body temperature.

- All types of drinks that contain added sugars should be avoided, including-, carbonated, concentrated juices etc.

- A healthy lifestyle should be followed. Physical activities like exercise, meditation, and regular sleep should be taken care of. Adequate sleep very necessary as it helps in supporting the normal functioning of immune system.
- To stay safe and avoid the chance of being exposed to corona virus, it is advised to eat at home.

\section{Beneficial Nutrient Against Covid-19}

\section{Vitamin C}

Vitamin $\mathrm{C}$ also known as ascorbic acid, is a well-known water-soluble vitamin. It is not synthesized by humans; thus, it must be consumed orally. It is an antioxidant and can hunt down reactive oxygen species (ROS), hence, it protects proteins, lipids and nucleotides present in the body from oxidative damage and dysfunction (Sharma, 2020)

Vitamin $\mathrm{C}$ is also famous for its abilities to fight and provide protection against infections \& diseases. Vit C supplement also help in supporting the respiratory defence mechanisms and associated with prevention of viral infections. Vit $\mathrm{C}$ has antihistamine properties which also helps in reducing the duration and as well as the severity of infections. Evidences suggest that administering Vit $\mathrm{C}$ in elderly patients with low plasma Vit $\mathrm{C}$ levels, suffering from acute respiratory infections such as pneumonia or tuberculosis, leads to reduced severity and duration of pneumonia (Hunt et al., 1994). As per the data of Covid 19, patients suffering from this disease are at high risk of developing pneumonia, this property of Vit $\mathrm{C}$ can help out in the treatment of the respiratory infection. A 
study showed that intravenous administration of vitamin $\mathrm{C}$ have helped in treatment of Covid 19 by showing improvements in inflammatory biomarkers and some respiratory parameters. In another case study of a patient who was on ventilator after she developed ARDS, when was treated with high doses of vitamin $\mathrm{C}$, was removed from the machine after 5 days which was earlier in comparison to other similar cases, however it should also be kept in notice that the patient was also on anti-viral medications. Therefore, supplementation with vitamin $\mathrm{C}$ seems to be an good idea for treatment of patients who are at risk of developing COVID-19 infection, and also to provide support to their immune system (Hiedra et al, 2020; Waqas et al, 2020).

Zinc

Zinc, one of the key trace minerals has been involved in many human biological processes including immunity boosting. Zinc has shown its inhibitory properties against the synthesis, replication, and transcription complex of coronaviruses ( $\mathrm{Te}$ Velthuis et al., 2010). It acts against the viral infections as it has the ability of directly interfering with the synthesis of protein $\&$ replication of the virus, proving its beneficial and therapeutic effects against viral infections (Skalny et al, 2020)).
A case study showed improved clinical symptoms in patients of Covid-19 when they were treated with high-dose zinc (Finzi, 2020). Studies have also shown that supplementing the Covid -19 patient with zinc supplementation can also decrease symptoms such as lower respiratory tract infection. These effects of zinc can be related to their inhibitory effect against have been viral uncoating, binding and replication, and may be relevant to COVID-19 (Shakoor et al., 2021).

\section{Omega-3-fatty acids}

Omega-3 fatty acids are polyunsaturated fatty acids and include eicosapentaenoic and docosahexaenoic fatty acids and are well known to have favorable effects on immunity and inflammation. Of interest, omega-3 fatty acids exert anti-viral effects by inhibiting influenza virus replication. According to the European Society for Parenteral and Enteral Nutrition expert statement, the use of omega-3 fatty acids may improve oxygenation in COVID-19 patients, although firm evidence is still missing (Barazzoni et al, 2020). Others however have suggested caution in the use of the omega-3 $\mathrm{s}$ in COVID-19 patients, citing evidence showing a counter-intuitive increase in oxidative stress and inflammation due to increased susceptibility of cellular membranes to damage (Rogero et al., 2020). 


\section{Vitamin E}

"Alpha-tocopherol," commonly known as Vit $\mathrm{E}$ is one of the major antioxidants. It helps to maintain the integrity of the cell membrane by enhanced antibody production, proliferation of lymphocytes and due to its natural property of killer cells, in turn enhancing the immune function of the body. Vit $\mathrm{E}$ also can inhibit the production of pro-inflammatory cytokines thus, limiting inflammation. Deficiency of this vitamin impairs immunity and increases susceptibility to infections, whether humoral and cell mediated. Although not much data is available to support use of vitamin $\mathrm{E}$ for the treatment of Covid 19 disease and different studies are still underway for proving its efficacy. It can be a potential nutrient for treatment because of its effects on immune function (Meydani et al., 1990; De la Fuente, M et al., 2008).

In a small clinical trial conducted in Mexico, patients with covid-19 resulted pneumonia were treated with $800 \mathrm{mg}$ vitamin E with Pentoxifylline drug for five days at every 12 hours. Another group with the same condition was treated only with Pentoxifylline. The results showed that those patients who were treated with the combination of drug and vitamin $\mathrm{E}$ had decreased levels of the inflammatory markers interleukin-6 and procalcitonin, then those treated with the drug alone. A significant decrease was also noticed in the levels of lipid peroxidation index (a measure of oxidative stress) with increased levels of nitrite, which suggested higher oxygen levels and reduced inflammatory marker C-reactive protein levels were also seen (Chavarría et al., 2021).Intake of food items rich in Vitamin E levels can help strengthening of immune system. It can be found commonly in different food items including green leafy vegetable, nuts, seed $\&$ vegetable oils (Sharma, 2020)

\section{Selenium}

Selenium is also one of the essential minerals, which helps the body to immune system by $\mathrm{T}$-cell maturation and function and because of its natural killer cell activity. Selenium also acts as an antioxidant and is helpful in treatment of acute respiratory distress syndrome and organ failure by reducing the risk of infection and supporting both the innate and adaptive immune systems. Since selenium has shown to have antiviral, antiinflammatory, and immune-enhancing properties, many researches recommend its use in the treatment of Covid-19 and its infections borne out of it. In a one-day trail held in Spain, selenium supplementation in amount of $110 \mathrm{mcg}$ with ten other minerals \& vitamins, was found to be helpful in reducing the risk of hospitalization in covid 
patients. Sea foods, brazil nuts, meat, poultry, and dairy products, bread, cereals, and other grain products are rich sources of selenium (Bermano et al., 2021).

\section{Quercetin}

Quercetin is a polyphenolic compound, which is very commonly found in many vegetables, fruits, spices, and beverages including apple, oranges, lemon, berries, onions, broccoli, tea, cilantro, and red wine. It has shown to have the properties of being anti-inflammatory, antiviral and antioxidant along with having immunomodulatory effects. It also shows inhibitory activities against platelet aggregation (Bastaminejad \& Bakhtiyari, 2020).

According to some sources, because of the molecular structure and pharmacological properties of quercetin, it may help in the treatment covid 19 as it can inhibit the SARS-CoV-2 virus. Quercetin also helps in reduction of infection and protects the organs from damages, such as acute kidney injury (Aucoin et al., 2020).

\section{Beneficial Herbs}

Ashwagandha, is the common name of herb Withania somnifera, It belongs to the family of Solanaceae, and is also known by the names of Indian ginseng, poison gooseberry, or winter cherry etc. Tha major chemical compounds of this herb are Withaferin A, withanone, with anolide WS1, withanolide A to $\mathrm{Y}$, somnirol and with a somniferin A. Presence of these bioactive compounds imparts the anti-tumorigenic, anti-inflammatory, pro-apoptotic, antiangiogenic, and anti-invasive properties to the plant. With a somniferin A can hinder the access of corona virus by binding to the SARS-CoV-2 S protein and altering the $\mathrm{S}$ protein. The compounds with anone and with anoside $\mathrm{V}$ can inhibit the functions of SARS-CoV-2 main protease (Mpro). Thus, acting beneficial in treatment of Covid-19 diseae (Dhawan et al., 2021).

Guduchi, also known as Tinospora cordifolia, comes from the family of Menispermaceae. The major constituents of this plant are Tinosporin, Tinosporide, Cordifolide \& Phenyl prophyl glycoside. The study was conducted to show the efficacy of the herb against SARS-CoV-2 virus. The present bioactive compounds, because of their anti-viral properties showed positive results for the treatment against the virus (Sagar \& Kumar, 2020).

Other herbs and plants such as Tulsi (Ocimum Sanctum), Kalmegha (Andrographis paniculate), Neem (Azadirachta indica), Tvak (Cinnamomum verum Presl), Turmeric (Curcuma longa), Ginger (Zingiber officinale), Indian gooseberry (Phyllanthus emblica) etc has shown beneficial effects in the treatment of covid disease due to their anti- 
inflammatory \& anti-viral properties

(Ministry of Ayush, 2021).

\section{CONCLUSION}

The Covid 19 pandemic has led to an environment of fear and uncertainty. People are experiencing greater levels of insomnia, depression, and anxiety. In these scenarios of social distancing and lockdowns, not only the mental health but nutritional status of an individual is being affected adversely. It is very important to maintain a balance of our mental health. Nutrition can play a very crucial role in not just treating the disease but also in maintaining the mental as well as social wellbeing of an individual All the nutrients mentioned above play a very important part in it. So, it is important to understand that a balance of healthy lifestyle that includes healthy eating, adequate sleep and physical activities, is really necessary to lead a healthy and peaceful life, even during the times of pandemic situation like Covid-19.

\section{REFERENCES}

[1] Aman, F., \& Masood, S. (2020). How Nutrition can help to fight against COVID-19

Pandemic. Pakistan journal of medical sciences, 36(COVID19S4), S121-S123. https://doi.org/10.12669/pjms.36.C OVID19-S4.2776
[2] Anton, S.D., Miller, P.M.(2005). Do negative emotions predict alcohol consumption, saturated fat intake, and physical activity in older adults? Behav Modif;29:677-688.

[3] Aucoin, M., Cooley, K., Saunders, P.R., Cardozo, V., Remy, D., Cramer, H., et al.(2020). The effect of quercetin on the prevention or treatment of COVID-19 and other respiratory tract infections in humans: A rapid review. Adv Integr Med,7;247-51

[4] Ball, K., and Lee, C. (2000). Relationships between psychological stress, coping, and disordered eating: a review. Psychol. Health 14; $1007-$ 1035. doi:

\section{$10.1080 / 08870440008407364$}

[5] Barazzon,i R., Bischoff, S.C., Krznaric, Z., Pirlich, M., \& Singer P.(2020). ESPEN Expert Statements and Practical Guidance for Nutritional Management of Individuals With SARS-CoV-2 Infection; 1631-1638.

[6] Bastaminejad, S., Bakhtiyari, S.(2020). Quercetin and its relative therapeutic potential against COVID-19: A retrospective review and prospective overview. Curr Mol Med 2020. 
[7] Beeching, N.F.T., \& Fowler, R.(2019). Coronavirus disease 2019 (COVID-19). BMJ Best Practice. 2020.

[8] Bermano, G., Méplan, C., Mercer, D.K., Hesketh, J.E. (2021). Selenium and viral infection: are there lessons for COVID-19? The Br J Nutr, 125;618-27.

[9] Bogoch, I.I., Watts, A., ThomasBachli, A., Huber, C., Kraemer, M.U., \& Khan, K.(2020). Pneumonia of unknown etiology in Wuhan, China:potential for international spread via commercial air travel. J Travel Med;272:1-3

[10] Cacioppo, J. T., and Hawkley, L. C. (2009). Perceived social isolation and cognition. Trends Cogn. Sci. 13;447-454. doi: 10.1016/j.tics.2009.06.005

[11] Cascella,M., Rajnik, M., Aleem, A., et al.(2022). Features, Evaluation, and Treatment of Coronavirus (COVID-19)

[Updated 2022 Jan 5].Treasure Island (FL): StatPearls Publishing; 2022 Jan

[12] Chan, J.F., Kok, K.H., Zhu, Z., Chu, K.K., Yuan, T.S., Yuen, K.Y., et al. (2020). Genomic characterization of the 2019 novel human-pathogenic coronavirus isolated from a patient with atypical pneumonia after visiting Wuhan. Emerg Microb Infect. 9:221-36.

[13] Chavarría, A.P., Vázquez, R.R.V., Cherit, J.G.D., Bello, H.H., Suastegui, H.C., MorenoCastañeda, L., et al.(2021).Antioxidants and pentoxifylline as coadjuvant measures to standard therapy to improve prognosis of patients with pneumonia by COVID-19. Comput Struct Biotechnol J,19;1379-90.

[14] Chen, T., Wu, D., Chen, H.(2020). Clinical characteristics of 113 deceased patients with coronavirus disease 2019: retrospective study [published correction appears in BMJ. $2020 \quad$ Mar 31;368:m1295] BMJ;368:m1091.

[15] Chen, Y., and Feeley, T. H. (2014). Social support, social strain, loneliness, and well-being among older adults: an analysis of the health and retirement study. $J$. Soc. Pers. Relat. 31; 141-161.

[16] Cheng, C. \& Cheung, M. W. (2005). Psychological responses to outbreak of severe acute respiratory syndrome: A prospective, multiple time-point 
study. Journal

of

Personality, 73 (1); 261-285.

[17] Cui, J., Li, F., Shi, Z.L.(2019).

Origin and evolution of pathogenic coronaviruses. Nat Rev Microbiol. 17;181-92.

[18] De la Fuente, M., Hernanz, A., Guayerbas, N., Victor, V.M., Arnalich, F.(2008). Vitamin E ingestion improves several immune functions in elderly men and women. Free Radic Res, $42 ; 272-80$.

[19] Dhawan, M.,Parmar, M.,Khan, S., Tiwari, R., Bilal, M.,\& Dhama, K. (2021). Medicinal and therapeutic potential of withanolides from Withania somnifera against COVID-19. Journal of Applied Pharmaceutical Science,11;006013. 10.7324/JAPS.2021.110402.

[20] Finzi, E.(2020). Treatment of SARS-CoV-2 with high dose oral zinc salts: a report on four patients. Int. J. Infect. Dis. 2020

[21] Han, C., Duan, C., Zhang, S., et al.(2020).Digestive symptoms in COVID-19 patients with mild disease severity: clinical presentation, stool viral RNA testing, and outcomes. Am J Gastroenterol ;115:916-923.
[22] Han, P. K. , Zikmund-Fisher, B. J. , Duarte, C. W. et al.(2018). Communication of scientific uncertainty about a novel pandemic health threat: ambiguity aversion and its mechanisms. Journal of Health Communication, 23, 435-444.

[23] Hiedra,R., Lo, K.B., Elbashabsheh, M., Gul, F., Wright, R.M., Albano, J., Azmaiprashvili, Z., Patarroyo Aponte, G.(2020). The use of IV vitamin $\mathrm{C}$ for patients with COVID-19: a single center observational study. Expert Rev. Anti. Ther. 2020

[24] Hunt, C., Chakravorty, N., Annan, G., Habibzadeh, N., Schorah, C.(1994). The clinical effects of vitamin $\mathrm{C}$ supplementation in elderly hospitalised patients with acute respiratory infections. Int. $J$. Vitam. Nutr. Res, 64(3);212-219.

[25] Kampf, G., Todt, D., Pfaender, S., Steinmann, E.(2020). Persistence of coronaviruses on inanimate surfaces and their inactivation with biocidal agents. $J$ Hosp Infect, 104;246-51.

[26] Khayyatzadeh, S.S.(2020). Nutrition and Infection with COVID-19.J Nutr Food Security, 5(2);93-96 
[27] López-Bueno, R., Calatayud, J., Casaña, J., Casajús, J. A., Smith, L., Tully, M. A., et al. (2020). COVID-19 Confinement and health risk behaviors in Spain. Front. Psychol, 11;1426. doi: 10.3389/fpsyg.2020.01426

[28] Mehta, P., McAuley, D.F., Brown, M.(2020). COVID-19: consider cytokine storm syndromes and immunosuppression. Lancet, 395; 1 033-1034. doi: 10.1016/S01406736(20)30628-0.

[29] Meydani, S.N., Barklund, M.P., Liu, S., Meydani, M., Miller, R.A., Cannon, J.G., et al.(1990). Vitamin E supplementation enhances cell-mediated immunity in healthy elderly subjects. Am J Clin Nutr,52;557-63.

[30] Ministry of AYUSH, Government of India. (2021). 20 Medicinal Plants of '21 for Covid 19 Care. https://www.nhp.gov.in/NHPfiles/ Final_e-book.pdf

[31] Parasa, S., Desai, M., Chandrasekar, V., et al.(2020).Prevalence of gastrointestinal symptoms and fecal viral shedding in patients with coronavirus disease 2019. A systematic review and metaanalysis. JAMA. 2020;3:0
[32] Perrin, P. C. , McCabe, O. L. , Everly, G. S. \& Links, J. M. (2009). Preparing for an influenza pandemic: Mental health considerations. Prehospital and Disaster Medicine, 24 (3);223230.

[33] Pfefferbaum, B., \&North, C.(2020).Mental health and the Covid-19 pandemic. $N$ Engl J Med [34] Pietrobelli, A., Pecoraro, L., Ferruzzi, A., Heo, M., Faith, M., Zoller, T., et al. (2020). Effects of COVID-19 lockdown on lifestyle behaviours in children with obesity living in Verona, Itlay: a longitudinal study. Obesity doi: 10.1002/oby.22861

[35] Rabi, F.A., Al Zoubi, M.S., Kasasbeh, G.A., Salameh, D.M., Al-Nasser, A.D.(2020). SARSCoV-2 and coronavirus disease 2019: What we know so far. Pathogens, 9;231. doi: 10.3390/pathogens 9030231

[36] Recalcati, S.(2020).Cutaneous manifestations in COVID- 19: a first perspective.. $J$ Eur Acad Dermatol,34;0

[37] Ren, S.-Y., Gao, R.D., \& Chen, Y.L. (2020). Fear can be more harmful than the severe acute respiratory syndrome coronavirus 
2 in controlling the corona virus disease 2019 epidemic. World Journal of Clinical Cases, 8 (4); 652-657

[38] Rogero, M.M., Leão, Md.C., Santana, T.M., Pimentel, M.Vd.M.B., Carlini, G.C.G., da Silveira, T.F.F., Gonçalves, R.C., Castro, I.A.(2020). Potential benefits and risks of omega-3 fatty acids supplementation to patients with COVID-19. Free Radic. Biol. Med,156;190-199.

[39] Sagar,V., Kumar, A.H.S.(2020).Efficacy of natural compounds from Tinospora cordifolia against SARS-CoV-2 protease, surface glycoprotein and RNA polymerase. J. of Virology;1-10.

[40] Sarma, A., \& Calfee, C. (2020). Prone positioning in awake nonincubated patients with COVID- 19: necessity is the mother of invention. JAMA Intern Med. 2020

[41] Shakoor, H., Feehan, J., Al Dhaheri, A. S., Ali, H. I., Platat, C., Ismail, L. C., Apostolopoulos, V., \& Stojanovska, L. (2021). Immune-boosting role of vitamins D, C, E, zinc, selenium and omega-3 fatty acids: Could they help against COVID19?. Maturitas, 143;1-9.

https://doi.org/10.1016/j.maturitas. $\underline{2020.08 .003}$

[42] Skalny ,A.V., Rink, L., Ajsuvakova, O.P., Aschner, M., Gritsenko, V.A., Alekseenko, S.I., Svistunov, A.A., Petrakis, D., Spandidos, D.A., Aaseth, J.(2020). Zinc and respiratory tract infections: perspectives for COVID-19. Int. J. Mol. Med,46(1);17-26.

[43] Solomon, I., Normandin, E., Bhattacharyya, S., et al.(2020).Neuropathological features of Covid-19. $N$ Engl $J$ Med. 2020

[44] L.Sharma : Dietary management to build adaptive immunity against COVID19 : Journal of PeerScientist . 2020: 2(2):25817221, pg e100016

[45] L Sharma (2020) Immunomodulatory effect and supportive role of traditional herbs, spices and nutrients in management of COVID-19, Journal of PeerScientist 3(2): e1000026. 2581-7221:pg 1-8:Sept 9,2020

[46] L Sharma : Management Against COVID-19 through Nutritional 
Supplementation to build Adaptive

Immunity - A Systematic Review:

International Journal of

Pharmaceutical Sciences and

Research ; Vol. 11(9): 4114-4122.

E-ISSN: 0975-8232; P-ISSN:

2320-5148:IF- 1.230: Web of

Science:

http://dx.doi.org/10.13040/IJPSR.0

975-8232.11(9).4114-22: DOI -

10.13040/IJPSR.0975-

8232.11(9).4114-22:

Sept

2020/WOS

[47] Syed, A.(2020).Coronavirus: a mini-review. Int J Curr Res Med Sci,6;8-10.

[48] Sze, S., Pan, D., Nevill, C.R., Gray, L.J., Martin, C.A., Nazareth, J., Minhas, J.S., Divall, P., Khunti, K., Abrams, K.R., Nellums, L.B., Pareek, M. (2020). Ethnicity and clinical outcomes in COVID-19: A systematic review and metaanalysis. EClinicalMedicine,29;10 0630

[49] Te Velthuis, A.J., van den Worm, S.H., Sims, A.C., Baric, R.S., Snijder, E.J., van Hemert, M.J.(2010). Zn2+ inhibits coronavirus and arterivirus RNA polymerase activity in vitro and zinc ionophores block the replication of these viruses in cell culture. PLoS Pathog,6(11).

[50] Tyrrell, D.A., Bynoe, M.L.(1966).Cultivation of viruses from a high proportion of patients with colds. Lancet, 1;76-77.

[51] Van Doremalen, N., Bushmaker, T., Karesh, W.B., Munster, V.J.(2014). Stability of Middle East respiratory syndrome coronavirus in milk. Emerg. Infect Dis, 20;1263-4. doi: 10.3201/eid2007.140500

[52] Waqas, K.H.M., Parikh, N., Megala, S.M., Predeteanu, G.S.(2020). Unusual early recovery of a critical COVID-19 patient after administration of intravenous vitamin C. Am. J. Case Rep, 21

[53] Wardle, J., Steptoe, A., Oliver, G., and Lipsey, Z. (2000). Stress, dietary restraint, and food intake. J. Psychosom. Res, 48; 195-202. doi: 10.1016/S00223999(00)00076-3

[54] Zaim, S., Chong, J. H., Sankaranarayanan, V., \& Harky, A. (2020). COVID-19 and Multiorgan Response. Current problems in cardiology, 45(8); 100618. 
https://doi.org/10.1016/j.cpcardiol.

$\underline{2020.100618}$

[55] Zhou, P., Yang, X.L., Wang, X.G., et al.(2020).A pneumonia outbreak associated with a new coronavirus of probable bat origin. Nature 2020.

10.1038/s41586-020-2012-7 